\title{
Preoperative vitamin D deficiency and postoperative hypocalcemia in thyroid cancer patients undergoing total thyroidectomy plus central compartment neck dissection
}

\author{
Xiaofei Wang ${ }^{1,2}$, Jingqiang Zhu ${ }^{1}$, Feng Liu ${ }^{1}$, Yanping Gong ${ }^{1}$ and Zhihui Li ${ }^{1}$ \\ ${ }^{1}$ Department of Thyroid and Breast Surgery, West China Hospital, Sichuan University, Chengdu, China \\ ${ }^{2}$ Department of Head and Neck Surgery, Sichuan Cancer Hospital \& Institute, Chengdu, China \\ Correspondence to: Zhihui Li, email: westchinalzh@163.com \\ Keywords: vitamin D deficiency, hypocalcemia, thyroid cancer, total thyroidectomy \\ Received: September 20, $2016 \quad$ Accepted: April 11,2017 Published: May 08, 2017 \\ Copyright: Wang et al. This is an open-access article distributed under the terms of the Creative Commons Attribution License 3.0 \\ (CC BY 3.0), which permits unrestricted use, distribution, and reproduction in any medium, provided the original author and source \\ are credited.
}

\section{ABSTRACT}

Background: There appears to be a lack of consensus whether preoperative vitamin D deficiency (VDD) increases the risk of postoperative hypocalcemia and decreases the accuracy of postoperative parathyroid hormone (PTH) in predicting hypocalcemia in thyroid cancer patients undergoing total thyroidectomy (TT) plus central compartment neck dissection (CCND). This study aims to address these issues.

Method: All consecutive thyroid cancer patients who underwent TT plus CCND were retrospectively reviewed through a prospectively collected database between October 2015 and April 2016 in a tertiary referral hospital. The multivariate analysis was performed to identify the significant predictors for hypocalcemia. Receiver operator characteristic curve (ROC) was created and the area under the ROC was used to evaluate the predictive accuracy of postoperative PTH and compared between patients with or without VDD.

Results: A total of 186 patients were included. The incidence of VDD was $73.7 \%$ (137 patients). The incidence of biochemical and symptomatic hypocalcemia was similar in patients with or without VDD $(P=0.304$ and 0.657 , respectively $)$. Multivariate analysis showed that only postoperative PTH was an independent predictor of symptomatic hypocalcemia $(O R=8.05,95 \% C I=3.99-16.22 ; P=0.000)$. The area under the ROC was similar between patients with preoperative vitamin $D$ level $<20$ and $\geq 20 \mathrm{ng} / \mathrm{mL}(0.809$ versus $0.845, P=0.592)$.

Conclusion: VDD was not a significant risk factor for hypocalcemia following TT+CCND, and did not affect the accuracy of postoperative PTH as a predictor of postoperative hypocalcemia. Thus, routine preoperative screening for vitamin $D$ seems to be unnecessary.

\section{INTRODUCTION}

Transient hypocalcemia is the most common complication of total thyroidectomy (TT) $[1,2]$, which has been reported to occur in up to $54 \%$ of patients [3]. It is a challenge for thyroid surgeons since it often leads to increased biochemical test frequency and prolonged hospitalization time $[4,5]$. Although higher incidence has been reported by previous literature, causes and mechanisms of post-thyroidectomy hypocalcemia remain unclear. Many factors have been postulated to increase the risk of hypocalcemia following TT, including surgical trauma, devascularization, or inadvertent removal of the parathyroid glands, surgeon volume, extent of cervical lymph node dissection, and so on [6-10]. Recently, Vitamin D deficiency (VDD) has also been recognized as a risk factor for postoperative hypocalcemia following TT in patients with benign thyroid diseases (nontoxic multinodular goiter or Graves' disease) [11-14]. However, the evidence is scarce and somewhat inconsistent 
regarding this association in thyroid cancer patients [15-17]. Different from patients with benign thyroid diseases, the majority of thyroid cancer patients are usually underwent central compartment neck dissection (CCND) besides TT in China. These patients might more often experience postoperative hypocalcaemia.

Symptoms of hypocalcemia usually occur 24-48 hours after surgery, so accurate prediction has potential influence on management strategies and shorten hospital stay. Early postoperative serum parathyroid hormone (PTH) level has been considered to be an accurate marker for predicting the development of postoperative hypocalcemia [2, 3, 6]. However, preoperative VDD might lead to secondary hyperparathyroidism and an increased bone turnover, subsequently leading to an increased PTH level [18, 19], which would affect the accuracy of postoperative PTH in predicting postoperative hypocalcemia $[19,20]$, but other studies didn't confirm this influence $[15,16]$.

Therefore, in this study, we retrospectively analyzed our perspectively collected data to further clarify the association between preoperative vitamin D levels and postoperative hypocalcemia in thyroid cancer patients undergoing TT and CCND, a sub-population at high risk of developing hypocalcemia [9, 21, 22], which was a good model to analysis hypocalcemia risk. Furthermore, we also investigated whether preoperative vitamin D levels would affect the accuracy of postoperative PTH in predicting post-thyroidectomy hypocalcemia.

\section{RESULTS}

A total of 186 patients were included in this study. Among them, 140 (75.3\%) were female and 46 (24.7\%) male. The mean age of patients was $42.98 \pm 13.20$ years (range, 18-76 years). Of the 186 patients, 125 (67.2\%) cases underwent bilateral CCND, 68 (36.6\%) underwent MRND, and $64(35.0 \%)$ underwent parathyroid glands autotransplantation. The mean vitamin $\mathrm{D}$ level of the entire cohort was $16.8 \pm 6.89 \mathrm{ng} / \mathrm{mL}$. Of the patients, $23(12.4 \%)$ had serum 25OHD levels of $<10 \mathrm{ng} / \mathrm{mL}, 114$ (61.3\%) had serum 25OHD levels of 10-20 ng/mL, and 49 (26.3\%) had serum $25 \mathrm{OHD}$ levels of $>20 \mathrm{ng} / \mathrm{mL}$. The incidence of laboratory and symptomatic hypocalcemia was 53.2\% (99 patients) and 38.2\% (71 patients), respectively. The serum calcium levels returned to normal in all patients with hypocalcemia and the symptoms of hypocalcemia resolved in all patients with symptomatic hypocalcemia within one month after surgery. Only one patient had persistent symptoms of hypocalcemia with below normal PTH levels at six months after operation. This patient has a normal level of preoperative serum vitamin D (66.4 $\mathrm{nmol} / \mathrm{L})$.

The demographic and clinicopathological characteristics of patients in VDD and VDS groups were presented in Table 1. There was no significant difference between the groups regarding all the parameters, except the level of preoperative 25OHD (mean: $13.46 \mathrm{ng} / \mathrm{mL}$ vs. $26.12 \mathrm{ng} / \mathrm{mL}, P=0.000$ ). The incidence of biochemical hypocalcemia and symptomatic hypocalcemia was similar in two groups $(55.5 \%$ vs. $46.9 \%, P=0.304$ and $37.2 \%$ vs. $40.8 \%, P=0.657$, respectively). There were 23 patients with severely VDD $(<10 \mathrm{ng} / \mathrm{mL})$. Among them, the incidence of biochemical hypocalcemia and symptomatic hypocalcemia was $60.9 \%(14 / 23)$ and $47.8 \%(11 / 23)$, which was not different from that of patients with $25 \mathrm{OHD}$ level $>10 \mathrm{ng} / \mathrm{mL}(P=0.433$ and 0.309 , respectively).

Multiple logistic regression analysis showed that only postoperative PTH was an independent predictor of symptomatic hypocalcemia $(\mathrm{OR}=8.05,95 \% \mathrm{CI}=3.99$ $16.22 ; P=0.000)$. However, preoperative vitamin $\mathrm{D}$ level (using the cutoff value of 10 or $20 \mathrm{ng} / \mathrm{mL}$ ), parathyroid gland autotransplantation and extent of CCND were not associated with the development of symptomatic hypocalcemia (Table 2).

Table 3 compared the preoperative and postoperative PTH levels according to the vitamin D status and presence or absence of symptomatic hypocalcemia. A significant relationship was observed between postoperative PTH and hypocalcemia in patients with vitamin $\mathrm{D}$ deficiency or sufficiency (both $P=0.000$ ). There was also a significant difference in the percentage of postoperative PTH less than $1.6 \mathrm{pmol} / \mathrm{L}$ in patients with or without symptomatic hypocalcemia in both the groups $(P=0.000$ and 0.001 , respectively).

The ROC curves for postoperative PTH were created for both groups to assess the accuracy of PTH as a predictor for the development of post-TT hypocalcemia (Figure 1). The area under the ROC curves for patients with VDD and VDS were 0.809 and 0.845 , respectively $(P=0.592)$.

\section{DISCUSSION}

VDD has a high prevalence in many countries, which has a significant burden on public health owing to its association with bone disease, cancer, lipid metabolism defects, diabetes, and heart disease [23-25]. However, there is no consensus about the accurate definition of VDD. Although VDD is defined as a serum 25OHD level less than $10 \mathrm{ng} / \mathrm{mL}$ and VDI is defined as less than $20 \mathrm{ng} /$ $\mathrm{mL}$ by WHO criteria, most experts suggested it is more appropriate to set the cutoff at $20 \mathrm{ng} / \mathrm{mL}$ and $30 \mathrm{ng} / \mathrm{mL}$ for VDD and VDI, because serum 25OHD level is inversely associated with serum PTH until the former reached to 30 $\mathrm{ng} / \mathrm{mL}[24,26,27]$. Therefore, we adopted the cutoff of $20 \mathrm{ng} / \mathrm{mL}$ for VDD in the present study. According to this criterion, there was a high prevalence of VDD $(73.7 \%)$ in our cohort.

Vitamin D plays a critical role in calcium homeostasis by directly regulating the intestinal calcium absorption and indirectly regulating parathyroid hormone 
Table 1: The main characteristics of patients with vitamin $D$ deficiency and sufficiency

\begin{tabular}{|c|c|c|c|}
\hline Variables & VDD $(n=137)$ & $\operatorname{VDS}(n=49)$ & $P$ Value \\
\hline Age (years) & $42.0 \pm 12.8$ & $45.7 \pm 14.1$ & 0.099 \\
\hline Gender (female/male) & $102 / 35$ & $38 / 11$ & 0.666 \\
\hline Tumor size $(\mathrm{cm})$ & $1.9 \pm 0.34$ & $1.8 \pm 0.75$ & 0.530 \\
\hline Concomitant hashimoto's thyroiditis (\%) & $22(16.1)$ & $5(10.2)$ & 0.318 \\
\hline Bilaterality (\%) & $35(25.5)$ & $16(32.7)$ & 0.339 \\
\hline Extrathyroid extension (\%) & $92(67.2)$ & $29(59.2)$ & 0.315 \\
\hline \multicolumn{4}{|l|}{ No. of identified PTG } \\
\hline 4/3/2 PTG & $126 / 9 / 2$ & $45 / 2 / 2$ & 0.491 \\
\hline \multicolumn{4}{|l|}{ No. of PTG autotransplantation } \\
\hline 0/1/2 PTG & $89 / 41 / 7$ & $33 / 15 / 1$ & 0.620 \\
\hline \multicolumn{4}{|l|}{ Extent of CCND } \\
\hline Unilateral/Bilateral & $47 / 90$ & $14 / 35$ & 0.463 \\
\hline \multicolumn{4}{|l|}{ MRND } \\
\hline No/Unilateral/ Bilateral & $87 / 38 / 12$ & $31 / 15 / 3$ & 0.805 \\
\hline \multicolumn{4}{|l|}{ Stage } \\
\hline $\mathrm{T} 1 \mathrm{a} / \mathrm{T} 1 \mathrm{~b} / \mathrm{T} 2 / \mathrm{T} 3 / \mathrm{T} 4 \mathrm{a} / \mathrm{T} 4 \mathrm{~b}$ & $23 / 8 / 2 / 97 / 5 / 2$ & $7 / 6 / 2 / 31 / 2 / 1$ & 0.442 \\
\hline $\mathrm{N} 0 / \mathrm{N} 1 \mathrm{a} / \mathrm{N} 1 \mathrm{~b}$ & $62 / 31 / 44$ & $26 / 11 / 12$ & 0.559 \\
\hline Preoperative serum $\mathrm{Ca}(\mathrm{mmol} / \mathrm{L})$ & $2.28 \pm 0.07$ & $2.32 \pm 0.15$ & 0.903 \\
\hline Preoperative serum VD (ng/mL) & $13.46 \pm 3.59$ & $26.12 \pm 5.11$ & 0.000 \\
\hline Preoperative serum PTH (pmol/L) & $5.78 \pm 1.90$ & $5.23 \pm 1.59$ & 0.072 \\
\hline Postoperative serum PTH (pmol/L) & $2.95 \pm 1.89$ & $2.83 \pm 1.88$ & 0.710 \\
\hline Postoperative serum $\mathrm{Ca}(\mathrm{mmol} / \mathrm{L})$ & $1.95 \pm 0.17$ & $1.97 \pm 0.17$ & 0.347 \\
\hline Biochemical hypocalcemia (\%) & $76(55.5)$ & $23(46.9)$ & 0.304 \\
\hline Symptomatic hypocalcemia (\%) & $51(37.2)$ & $20(40.8)$ & 0.657 \\
\hline
\end{tabular}

Abbreviations: VDD: Vitamin D deficiency; VDS: Vitamin D sufficiency; PTG, Parathyroid gland; CCND, Central compartment neck dissection; MRND: modified radical neck dissection; Ca: Calcium; VD: Vitamin D; PTH: Parathyroid hormone. Serum factors were presented by mean \pm standard deviations.

(PTH) secretion via its effects on serum calcium. Therefore, preoperative vitamin D level might affect postoperative serum calcium and PTH metabolism. When patients have impaired parathyroid function, sufficient vitamin D could promote the intestinal calcium absorption to maintain calcium homeostasis. However, this regulatory mechanism of increased calcium absorption is damaged in the case of VDD $[13,28]$. Therefore, it seems to be reasonable that preoperative VDD should increase the incidence of postoperative hypocalcemia in patients undergoing TT + CCND, which usually suffered hypoparathyroidism because of parathyroid ischemia/ injury or inadvertent resection.

Very few studies have investigated the influence of VDD on postoperative hypocalcemia after TT + CCND with inconsistent results to date. Griffin et al [29] and Cherian et al [16] reported that VDD had no significant effect on the risk of postoperative hypocalcemia in patients underwent TT. However, both studies included heterogeneous population with a large number of patients with benign thyroid diseases and only a small number of patients undergoing concomitant CCND. Lee et al [30] reported that preoperative vitamin D level was not a predictor of hypocalcemia among a series of 134 patients with thyroid cancer underwent TT+CCND, whereas Kim et al [17] reported that VDD was a significantly factor for increased postoperative symptomatic hypocalcemia in a series of 267 patients undergoing TT plus CCND.

In the present study, to reduce potential confounders influence, we analyzed the data from a similar population 
Table 2: Linear logistic regression analysis between symptomatic hypocalcemia and independent parameters

\begin{tabular}{lcc}
\hline Parameters & Odds ratio (95\% CI) & $P$ value \\
\hline Postoperative PTH $<\mathbf{1 . 6} \mathbf{~ p m o l} / \mathbf{L}$ & $8.05(3.99-16.22)$ & $\mathbf{0 . 0 0 0}$ \\
Preoperative $\mathbf{2 5 O H D}<\mathbf{1 0} \mathbf{~ n g / m L}$ & $1.01(0.34-2.98)$ & 0.992 \\
Preoperative $\mathbf{2 5 O H D}<\mathbf{2 0} \mathbf{~ n g / m L}$ & $1.12(0.40-1.95)$ & 0.886 \\
Parathyroid gland autotransplantation & $1.94(0.94-4.01)$ & 0.073 \\
Bilateral CCND & $1.24(0.59-2.60)$ & 0.575 \\
\hline
\end{tabular}

Abbreviations: PTH, parathyroid hormone; 25OHD, 25-hydroxyvitamin D; CCND, central compartment neck dissection.

Table 3: Comparison of the preoperative and postoperative PTH levels according to their vitamin D level and presence or absence of symptomatic hypocalcemia

\begin{tabular}{|c|c|c|c|c|c|c|}
\hline & \multicolumn{3}{|c|}{$250 H D<20 \mathrm{ng} / \mathrm{mL}$} & \multicolumn{3}{|c|}{$250 H D \geq 20 \mathrm{ng} / \mathrm{mL}$} \\
\hline & \multicolumn{2}{|c|}{ Symptomatic hypocalcemia } & \multirow[t]{2}{*}{$P$ value } & \multicolumn{2}{|c|}{ Symptomatic hypocalcemia } & \multirow[t]{2}{*}{$P$ value } \\
\hline & $\begin{array}{c}\text { Presence } \\
(n=51)\end{array}$ & $\begin{array}{c}\text { Absence } \\
(n=86)\end{array}$ & & $\begin{array}{c}\text { Presence } \\
(n=20)\end{array}$ & $\begin{array}{c}\text { Absence } \\
(n=29)\end{array}$ & \\
\hline Preoperative PTH & $5.9 \pm 1.86$ & $5.7 \pm 1.92$ & 0.453 & $5.2 \pm 1.92$ & $5.2 \pm 1.35$ & 0.966 \\
\hline Postoperative PTH & $1.7 \pm 1.29$ & $3.7 \pm 1.81$ & 0.000 & $1.6 \pm 1.43$ & $3.7 \pm 1.73$ & 0.000 \\
\hline Postoperative PTH & $32(62.7)$ & $14(16.3)$ & 0.000 & $13(65.0)$ & $5(17.2)$ & 0.001 \\
\hline$<1.6 \mathrm{pmol} / \mathrm{L} \mathrm{n}(\%)$ & & & & & & \\
\hline
\end{tabular}

Abbreviations: 25OHD, 25-hydroxyvitamin D ; PTH, parathyroid hormone.

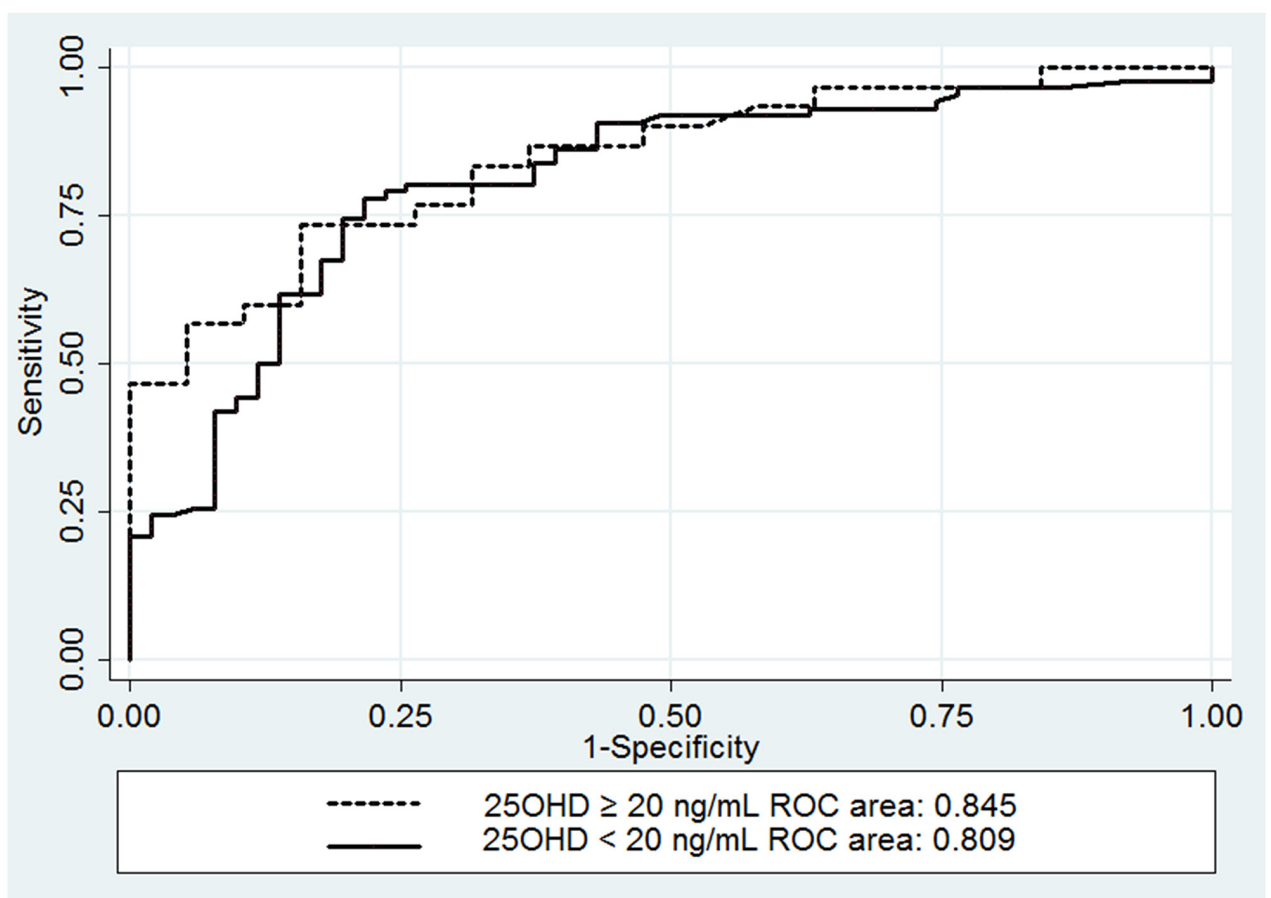

Figure 1: Receiver operator characteristic curves comparing the accuracy of serum PTH in predicting postthyroidectomy hypocalcemia in patients with a serum vitamin $D$ concentration $\geq 20 \mathrm{ng} / \mathrm{mL}$ and those with a serum vitamin $D$ concentration $<20 \mathrm{ng} / \mathrm{mL}$. 
with same pathology and similar surgery extent performed by an experienced thyroid surgeon. The result suggested that there was no significant association between preoperative serum vitamin D level and postoperative hypocalcemia in thyroid cancer patients underwent $\mathrm{TT}+\mathrm{CCND}$. This finding is consistent with that of Lee et al [30] but contrary to that of Kim et al [17]. Even if we defined VDD as vitamin D levels less than $10 \mathrm{ng} / \mathrm{mL}$, which was the cutoff value used by Kim et al [17], the result is still similar. One explanation for our findings may be due to the fact that 1,25 dihydroxyvitamin $\mathrm{D}$, converted from $25 \mathrm{OHD}$, is the biologically active form of vitamin $\mathrm{D}$, which is tightly regulated by PTH; post-thyroidectomy hypoparathyroidism results in decreased conversion of $25 \mathrm{OHD}$ to 1,25 dihydroxyvitamin $\mathrm{D}$, regardless of the amount of 25OHD available. Another probable reason is that a minor or weak effect of 25OHD on hypocalcemia has been covered by other confounders such as bilateral CCND and parathyroid antotransplantation, although these factors were not significant on the multivariate analysis.

In our study, we also evaluated whether preoperative VDD reduces the accuracy of postoperative PTH in predicting post-thyroidectomy hypocalcemia. The results showed the accuracy of postoperative PTH as a predictor for hypocalcemia appeared similar between patients with $25 \mathrm{OHD}<20$ and $\geq 20 \mathrm{ng} / \mathrm{mL}$ (Table 3 and Figure 1). This is consistent with the finding of Lang et al [15] and Cherian et al [16] studies. However, there are some different features between their studies and ours. Lang et al [15] defined VDD as $250 H D$ level $<15 \mathrm{ng} / \mathrm{mL}$. Cherian et al [16] study included considerably variable extent of surgery; with only 18.6\% patients underwent TT plus CCND. In contrast, other authors reported that postoperative serum PTH had lower accuracy in predicting hypocalcemia in patients with VDD when compared to patients without VDD. Sam et al [20] demonstrated that the area under the ROC curve for postoperative serum $\mathrm{PTH}$ to predict hypocalcemia in patients without VDD was 0.93 (95\% CI: $0.86-1.00 ; P=0.0001)$, but that of patients with VDD was 0.68 (95\% CI: 0.39-0.97; $P=0.23)$. It should be noted that the sample size is relatively small in that study; the total sample size is 74 , and only 16 patients suffered VDD. The smaller sample size may affect the accuracy of the results. Another study [19] also revealed that postoperative serum PTH was not a reliable predictor for hypocalcemia in patients with VDD based on a series of 203 cases. In their cases, the preoperative PTH level in VDD group was significant higher than that of control group (mean: 60.35 vs. $22.4 \mathrm{pg} / \mathrm{mL}, P=0.0001$ ), which suggested the presence of secondary hyperparathyroidism. The secondary hyperparathyroidism would influence the postoperative PTH level in VDD patients. However, the preoperative PTH level had no significant difference in patients with or without VDD (mean: 5.78 vs. $5.23 \mathrm{pmol} / \mathrm{L}, P=0.072$ ) in our study. Thus, the secondary hyperparathyroidism may explain the discrepancy between aforementioned study and ours.
It is worth noting that several limitations were present. First, although the study included a relatively homogeneous population of thyroid cancer patients and the operations were performed by a single surgeon, the sample size remains relatively small; our findings might have been purely the result of the underpowering of the study. However, based on a previous study [30], 57 subjects in each group (VDD and VDS) were enough to detect a difference of $15 \%$ in hypocalcemia using Flemming's model with a type 1 error $(\alpha)$ of 0.05 and a power $(\beta)$ of $80 \%$. Second, although there was a high incidence of VDD in our series, the number of patients with severe VDD $(<10 \mathrm{ng} / \mathrm{mL})$ was small (only 23 patients). Whether severe VDD increases the risk of hypocalcemia need to be further studied. Third, the surgical volume of the surgeon was significantly associated with the postoperative hypocalcemia of thyroid surgery [31-33]. Therefore, in order to eliminate the impact of the individual surgeon experience on postoperative complications, we only included the patients operated by a single experienced thyroid surgeon (ZH. Li), but which was a potential limitation for universality.

In conclusion, although VDD was common in our cohort, it was not a significant risk factor for hypocalcemia following TT $+\mathrm{CCND}$, and did not affect the accuracy of postoperative PTH as a predictor of post-thyroidectomy hypocalcemia. Thus, routine preoperative screening for vitamin D seems to be unnecessary.

\section{MATERIALS AND METHODS}

\section{Patients}

After approval of the Institutional Research and Ethical Board, we retrospectively analyzed the data of consecutive thyroid cancer patients undergoing TT with CCND by a single surgeon $(\mathrm{Li} \mathrm{ZH})$ in the department of thyroid and breast surgery of West China Hospital between October 2015 and April 2016. All patients who were more than 18 years old and pathologically confirmed papillary thyroid cancer were included. Patients with evidence of hyperthyroidism, concomitant parathyroid disease, metabolic bone disease, liver or renal dysfunction and patients with previous thyroid surgery were excluded. Patients with abnormal value of preoperative serum calcium, PTH, albumin or creatinine were also excluded from the study.

\section{Methods}

Surgical techniques have been described previously [10, 34]. Briefly, TT was performed using a capsular dissection technique with routine identification and preservation of the recurrent laryngeal nerves and parathyroid glands. Devascularized or inadvertently removed parathyroid glands were chopped into $1 \mathrm{~mm}^{3}$ fragments and autotransplanted into the non-tumor side sternocleidomastoid muscle. Intraoperative nerve 
monitoring and nano-carbon suspension were used to help identifying and preserving the recurrent laryngeal nerve and parathyroid glands in all patients. All patients underwent TT plus unilateral or bilateral CCND with or without modified radical neck dissection (MRND).

Preoperative vitamin D, serum calcium, albumin and PTH levels were measured within one week before surgery in all patients. Postoperative vitamin D, serum calcium and PTH levels were determined at each morning for three days after surgery. Serum calcium concentration was adjusted for serum albumin: adjusted calcium = $0.8 *(4.0$-serum albumin $)+$ serum calcium. Hypocalcemia was defined as adjusted serum calcium $<2.0 \mathrm{mmol} / \mathrm{L}$ with or without any clinical symptoms or signs of hypocalcemia, including numbness and paresthesias of the fingertips, toes, and perioral area, positive Chvostek's or Trousseau's sign, and tetany, which is a frequently used definition [2, 7, 29, 35]. All patients with asymptomatic hypocalcemia were treated with oral calcium (calcium carbonate 1.2-2.4 g/d). Symptomatic hypocalcemia was managed with parenteral calcium and an oral 1,25-dihydroxy vitamin D3 (calcitriol) supplementation of $0.5-1.0 \mathrm{~g} / \mathrm{d}$. Similar to other studies [11, 16, 28, 29], VDD was defined as serum 25-hydroxyvitamin D (25OHD) levels $<20 \mathrm{ng} / \mathrm{mL}$ in our study. 25 OHD levels $\geq 20 \mathrm{ng} / \mathrm{mL}$ defined as vitamin D sufficiency (VDS). No prophylactic oral calcium or vitamin D supplementation was administrated in the preoperative period. All the patients were divided into two groups (VDD and VDS). Reference ranges of biochemical parameters were $2.10-2.60 \mathrm{mmol} / \mathrm{L}$ for serum calcium, 1.60-6.90 pmol/L for serum PTH, and 47.7-144 nmol/L for serum 25-OHD concentrations (to convert to $\mathrm{ng} / \mathrm{mL}$, divide by 2.5 ) in our hospital.

\section{Statistical analysis}

Continuous variables data was presented as mean \pm standard deviation (SD). Categorical data was presented as frequency along with percentages. Independent sample $t$-test and Mann-Whitney $U$ test were used to compare continuous variables based on the data distribution, while Chi-square test or Fisher's exact test was used for categorical variables. To identify independent predictor of postoperative hypocalcemia, linear logistic regression analysis was performed. Receiver operator characteristic curve (ROC) was constructed and the area under the ROC was used to measure the predictive accuracy and compared between both groups. A $P$ value $<0.05$ was considered to be statistically significant. All analyses were performed using the SPSS 22.0 (SPSS, Inc., an IBM Company, Chicago, IL, USA) and Stata version 11.0 (Stata Corporation, College Station, TX, USA).

\section{CONFLICTS OF INTEREST}

None.

\section{REFERENCES}

1. Asari R, Passler C, Kaczirek K, Scheuba C, Niederle B. Hypoparathyroidism after total thyroidectomy: a prospective study. Arch Surg. 2008; 143:132-37.

2. Pisanu A, Saba A, Coghe F, Uccheddu A. Early prediction of hypocalcemia following total thyroidectomy using combined intact parathyroid hormone and serum calcium measurement. Langenbecks Arch Surg. 2013; 398:42330. https://doi.org/10.1007/s00423-012-1017-6.

3. Kara M, Tellioglu G, Krand O, Fersahoglu T, Berber I, Erdogdu E, Ozel L, Titiz MI. Predictors of hypocalcemia occurring after a total/near total thyroidectomy. Surg Today. 2009; 39:752-57.

4. Bhattacharyya N, Fried MP. Assessment of the morbidity and complications of total thyroidectomy. Arch Otolaryngol Head Neck Surg. 2002; 128:389-92.

5. Abboud B, Sargi Z, Akkam M, Sleilaty F. Risk factors for postthyroidectomy hypocalcemia. J Am Coll Surg. 2002; 195:456-61.

6. Edafe O, Antakia R, Laskar N, Uttley L, Balasubramanian SP. Systematic review and meta-analysis of predictors of post-thyroidectomy hypocalcaemia. Br J Surg. 2014; 101:307-20.

7. Lindblom P, Westerdahl J, Bergenfelz A. Low parathyroid hormone levels after thyroid surgery: a feasible predictor of hypocalcemia. Surgery. 2002; 131:515-20.

8. Sosa JA, Bowman HM, Tielsch JM, Powe NR, Gordon TA, Udelsman R. The importance of surgeon experience for clinical and economic outcomes from thyroidectomy. Ann Surg. 1998; 228:320-30.

9. Giordano D, Valcavi R, Thompson GB, Pedroni C, Renna L, Gradoni P, Barbieri V. Complications of central neck dissection in patients with papillary thyroid carcinoma: results of a study on 1087 patients and review of the literature. Thyroid. 2012; 22:911-7. https://doi.org/10.1089/ thy.2012.0011.

10. Wang X, Xing T, Wei T, Zhu J. Completion thyroidectomy and total thyroidectomy for differentiated thyroid cancer: comparison and prediction of postoperative hypoparathyroidism. J Surg Oncol. 2016; 113:522-25.

11. Al-Khatib T, Althubaiti AM, Althubaiti A, Mosli HH, Alwasiah RO, Badawood LM. Severe vitamin D deficiency: a significant predictor of early hypocalcemia after total thyroidectomy. Otolaryngology — head and neck surgery : official journal of American Academy of Otolaryngology-. Head Neck Surg. 2015; 152:424-31.

12. Erbil Y, Barbaros U, Temel B, Turkoglu U, Işsever H, Bozbora A, Ozarmağan S, Tezelman S. The impact of age, vitamin $\mathrm{D}(3)$ level, and incidental parathyroidectomy on postoperative hypocalcemia after total or near total thyroidectomy. Am J Surg. 2009; 197:439-46.

13. Kirkby-Bott J, Markogiannakis H, Skandarajah A, Cowan M, Fleming B, Palazzo F. Preoperative vitamin D 
deficiency predicts postoperative hypocalcemia after total thyroidectomy. World J Surg. 2011; 35:324-30.

14. Nhan C, Dolev Y, Mijovic T, Rivera JA, Kallai-Sanfaçon MA, Mlynarek AM, Payne RJ. Vitamin D deficiency and the risk of hypocalcemia following total thyroidectomy. J Otolaryngol Head Neck Surg. 2012; 41:401-06.

15. Lang BH, Wong KP, Cowling BJ, Fong YK, Chan DK, Hung GK. Do low preoperative vitamin D levels reduce the accuracy of quick parathyroid hormone in predicting postthyroidectomy hypocalcemia? Ann Surg Oncol. 2013; 20:739-45.

16. Cherian AJ, Ponraj S, Gowri S M, Ramakant P, Paul TV, Abraham DT, Paul MJ. The role of vitamin D in postthyroidectomy hypocalcemia: still an enigma. Surgery. 2016; 159:532-38.

17. Kim WW, Chung SH, Ban EJ, Lee CR, Kang SW, Jeong JJ, Nam KH, Chung WY, Park CS. Is Preoperative Vitamin D Deficiency a Risk Factor for Postoperative Symptomatic Hypocalcemia in Thyroid Cancer Patients Undergoing Total Thyroidectomy Plus Central Compartment Neck Dissection? Thyroid. 2015; 25:911-8.

18. Lips P. Vitamin D deficiency and secondary hyperparathyroidism in the elderly: consequences for bone loss and fractures and therapeutic implications. Endocr Rev. 2001; 22:477-501.

19. Pradeep PV, Ramalingam K. Postoperative PTH measurement is not a reliable predictor for hypocalcemia after total thyroidectomy in vitamin D deficiency: prospective study of 203 cases. World J Surg. 2014; 38:564-67.

20. Sam AH, Dhillo WS, Donaldson M, Meeran K, Tolley NS, Palazzo FF. Serum parathyroid hormone is not an accurate predictor of postthyroidectomy hypocalcemia in vitamin D-deficient patients: a pilot study. Clin Chem. 2011; 57:1206-07.

21. El Malki HO, Abouqal R. Systematic review and metaanalysis of predictors of post-thyroidectomy hypocalcaemia (Br J Surg 2014; 101: 307-320). Br J Surg. 2014; 101:883.

22. Palestini N, Borasi A, Cestino L, Freddi M, Odasso C, Robecchi A. Is central neck dissection a safe procedure in the treatment of papillary thyroid cancer? Our experience. Langenbecks Arch Surg. 2008; 393:693-8. https://doi. org/10.1007/s00423-008-0360-0.

23. Nakashima A, Yokoyama K, Yokoo T, Urashima M. Role of vitamin $\mathrm{D}$ in diabetes mellitus and chronic kidney disease. World J Diabetes. 2016; 7:89-100.
24. Holick MF. Vitamin D deficiency. N Engl J Med. 2007; 357:266-81.

25. Deeb KK, Trump DL, Johnson CS. Vitamin D signalling pathways in cancer: potential for anticancer therapeutics. Nat Rev Cancer. 2007; 7:684-700.

26. Holick MF, Siris ES, Binkley N, Beard MK, Khan A, Katzer JT, Petruschke RA, Chen E, de Papp AE. Prevalence of Vitamin D inadequacy among postmenopausal North American women receiving osteoporosis therapy. J Clin Endocrinol Metab. 2005; 90:3215-24.

27. Thomas MK, Lloyd-Jones DM, Thadhani RI, Shaw AC, Deraska DJ, Kitch BT, Vamvakas EC, Dick IM, Prince RL, Finkelstein JS. Hypovitaminosis D in medical inpatients. N Engl J Med. 1998; 338:777-83.

28. Tripathi M, Karwasra RK, Parshad S. Effect of preoperative vitamin D deficiency on postoperative hypocalcemia after thyroid surgery. Thyroid Res. 2014; 7:8.

29. Griffin TP, Murphy MS, Sheahan P. Vitamin D and risk of postoperative hypocalcemia after total thyroidectomy. JAMA Otolaryngol Head Neck Surg. 2014; 140:346-51.

30. Lee GH, Ku YH, Kim HI, Lee MC, Kim MJ. Vitamin $\mathrm{D}$ level is not a predictor of hypocalcemia after total thyroidectomy. Langenbecks Arch Surg. 2015; 400:617-22.

31. Duclos A, Peix JL, Colin C, Kraimps JL, Menegaux F, Pattou F, Sebag F, Touzet S, Bourdy S, Voirin N, Lifante JC, Group CS, and CATHY Study Group. Influence of experience on performance of individual surgeons in thyroid surgery: prospective cross sectional multicentre study. BMJ. 2012; 344:d8041.

32. Loyo M, Tufano RP, Gourin CG. National trends in thyroid surgery and the effect of volume on short-term outcomes. Laryngoscope. 2013; 123:2056-63.

33. Noureldine SI, Abbas A, Tufano RP, Srivastav S, Slakey DP, Friedlander P, Kandil E. The impact of surgical volume on racial disparity in thyroid and parathyroid surgery. Ann Surg Oncol. 2014; 21:2733-39.

34. Wei T, Li Z, Jin J, Chen R, Gong Y, Du Z, Gong R, Zhu J. Autotransplantation of Inferior Parathyroid glands during central neck dissection for papillary thyroid carcinoma: a retrospective cohort study. Int J Surg. 2014; 12:1286-90.

35. Erbil Y, Bozbora A, Ozbey N, Issever H, Aral F, Ozarmagan $\mathrm{S}$, Tezelman S. Predictive value of age and serum parathormone and vitamin $\mathrm{d} 3$ levels for postoperative hypocalcemia after total thyroidectomy for nontoxic multinodular goiter. Arch Surg. 2007; 142:1182-87. 